\title{
Produção de Lamelas em Serra de Fita Horizontal Múltipla para Fabricação de Piso Engenheirado de Madeira
}

\author{
Raquel Marchesan ${ }^{1}$, Luis Fernando Fonseca Kasprzak², \\ Elisangela Lobo Schirigatti ${ }^{1}$, Ricardo Jorge Klitzke ${ }^{1}$, Márcio Pereira da Rocha ${ }^{1}$ \\ ${ }^{1}$ Departamento de Ciências Florestais, Universidade Federal do Paraná - UFPR, Curitiba/PR, Brasil \\ ${ }^{2}$ Departamento de Design, Pontifícia Universidade Católica do Paraná - PUCPR, Curitiba/PR, Brasil
}

\section{RESUMO}

Este trabalho teve como objetivo estudar a relação da velocidade de avanço de um modelo de serra fita horizontal na qualidade final das lamelas de quatro espécies de madeira utilizadas na produção de pisos engenheirados: jatobá (Hymenaea courbari L.), muiracatiara (Astronium lecointei), amendoim (Pterogyne nitens) e sucupira (Bowdichia nitida). Foram estudadas as distribuições das espessuras das lamelas com relação à velocidade de avanço, considerando-se o tipo de madeira, a especificação do controle de qualidade e a existência de marcas na superfície. Os resultados mostraram que o amendoim apresentou maior aproveitamento na produção de lamelas, enquanto que o jatobá foi a espécie que sofreu maior perda no processo de produção. A velocidade de avanço que apresentou os menores índices de desclassificação de lamelas foi de $8 \mathrm{~m} / \mathrm{min}$, sendo a mais indicada para produção de lamelas.

Palavras-chave: velocidade de avanço, piso engenheirado, qualidade.

\section{Production of Lamellae in Multiple Horizontal Band Saws for the Manufacturing Engineered Wood Flooring}

\begin{abstract}
In this research, we aimed to study the forward speed rate (feed rate) of a horizontal band saw model in the final quality of the lamellae from four wood species used in the production of engineered flooring, Jatoba (Hymenaea courbaril L.) Muiracatiara (Astronium lecointei), Amendoim (Pterogyne nitens ) and Sucupira (Bowdichia nitida). The distributions of the lamellae thicknesses were studied with respect to forward speed, considering the type of wood, specification of quality control, and existence of surface markings. Results showed that the Amendoim presented greater benefits to the production of lamellae, whereas the Jatoba was the species that showed the greatest loss during the production process. The feed rate of $8 \mathrm{~m} / \mathrm{min}$ presented the lowest declassification of lamellae, being the most suitable for engineered wood flooring production.
\end{abstract}

Keywords: forward speed, engineered flooring, quality. 


\section{INTRODUÇÃO}

As dificuldades no uso da madeira em processos de fabricação de pisos estão baseadas no conhecimento de como trabalhar corretamente esse material. É preciso conhecer sua estrutura e seus parâmetros de usinagem para entender as relações que proporcionam os bons resultados em qualidade.

Segundo Kininmonth e Whitehouse (1991), a qualidade obtida não é um aspecto pontual e sim uma relação ampla de todas as propriedades do material trabalhado. Contudo, é importante verificar a variação dessas propriedades por meio de medições macro e microscópicas. Os principais defeitos no processo de usinagem da madeira estão ligados a três fontes básicas: as propriedades da madeira; as características de funcionamento das máquinas e das ferramentas de corte, e, por último, o treinamento da mão de obra. Esses parâmetros fornecem informações úteis para o controle da qualidade do processo de fabricação do piso engenheirado de madeira.

Em um estudo de caso realizado por Coletti et al. (2010), observou-se que $52,6 \%$ dos defeitos encontrados na produção do piso engenheirado referem-se a defeitos nas lamelas, como marcas de serra, seguidas por rachadura; empenamento; furos de inseto; variação de largura; encanoamento; variação de espessura; ponta quebrada, e variação de comprimento.

O termo usinagem ou trabalhabilidade refere-se ao grau de facilidade de processar a madeira mediante o uso de instrumentos, tendo como objetivo não somente desdobrá-la, mas produzir uma forma desejada quanto às dimensões e à qualidade da superfície, tão exato e econômico quanto for possível (Latorraca, 2000).

Coletti et al. (2010) comentam que a velocidade de avanço, o desgaste do dente da serra, a dureza da madeira, a falta de instrução durante o corte da madeira e a falta de treinamento dos operadores da máquina são alguns fatores que podem interferir na qualidade de obtenção das lamelas.

Conforme as características da ferramenta, vários resultados são afetados, tais como vida útil da ferramenta, produtividade e qualidade da peça usinada. Essas características são, basicamente, a geometria de corte e o material da ferramenta. Além disso, irão influir decisivamente as condições de corte para cada espécie de madeira (Lucas Filho, 2004).

Segundo Stemmer (2001), para avaliar o grau de usinabilidade de um material, são empregados, com frequência, os seguintes parâmetros: a vida útil da ferramenta, as forças que atuam sobre a ferramenta e a potência consumida pela máquina, além da qualidade do acabamento da superfície obtida pela usinagem. Estes critérios também influem decisivamente no custo do trabalho de usinagem realizado na fabricação de uma determinada peça.

Segundo Boehs (1988) apud Lucas Filho (2004), as ferramentas de corte necessitam possuir uma série de propriedades para atender às diferentes solicitações a que estão sujeitas. No caso da usinagem da madeira, são de particular interesse a resistência à abrasão, a tenacidade, a rigidez e a estabilidade química, em razão da possibilidade de oxidação da ferramenta.

De acordo com a Associação Nacional dos Produtores de Pisos de Madeira, as principais espécies de madeiras utilizadas para a fabricação de pisos são: cabreúva-vermelha, jatobá, pau-amarelo, cumaru, maçaranduba, pau-marfim, goiabão, muirapiranga, tatajuba, ipê, muiracatiara e tauari (ANPM, 2010).

\section{MATERIAL E MÉTODOS}

Para alcançar os objetivos propostos, utilizou-se de dados primários coletados na empresa Scandian Wood Floors, localizada em São José dos Pinhais, região metropolitana de Curitiba-PR. A empresa produz pisos engenheirados de madeira tropical. A maior parte de sua produção é voltada para o mercado externo, sendo que, em decorrência do novo cenário econômico, a empresa vem desenvolvendo novos produtos que atendam também a necessidade do mercado interno.

Para orientar o processo investigativo, foi desenvolvida de maneira não direcional uma hipótese nula (H0) e uma hipótese alternativa (H1) para cada questão de pesquisa, com o uso de um nível de significância de 0,05 (a). A partir de então, o plano de pesquisa foi dividido em procedimentos 
de investigação e operacionalização das variáveis, e análise das aplicações dos testes estatísticos.

a) Características das espécies estudadas

A seguir, estão relacionadas as características gerais das espécies de madeira utilizadas para o estudo:

- Jatobá (Hymenaea courbaril L.) - a madeira de jatobá possui massa específica aparente a $15 \%$ de umidade de $0,96 \mathrm{~g} / \mathrm{cm}^{3}$ e é considerada madeira muito pesada e muito dura ao corte (Mainieri e Chimelo, 1989). É moderadamente fácil de trabalhar, pode ser aplainada e colada. $\mathrm{O}$ acabamento é bom. Aceita pintura e verniz (ANPM, 2010).

- Muiracatiara (Astronium Lecointei) - madeira moderadamente fácil de ser trabalhada. A madeira possui massa específica aparente a $15 \%$ de umidade de $0,97 \mathrm{~g} / \mathrm{cm}^{3}$ e é considerada muito pesada e muito dura ao corte (Mainieri e Chimelo, 1989). Possui textura média e homogênea, alto brilho nas superfícies longitudinais e grã ondulada (IBDF, 1988). Entretanto, a madeira mostra uma superfície áspera após o aplainamento. A madeira de muiracatiara propicia excelente acabamento, recebendo bem pintura, verniz, lustro e emassamento (IBAMA, 2011).

- Sucupira (Bowdichia nitida) - madeira de difícil trabalhabilidade, razão da impermeabilidade do cerne. É de difícil aplainamento, fácil de ser torneada e tem ótima aceitação de pregos e parafusos, apresentando bom acabamento (IBDF, 1988). Possui massa específica aparente a $15 \%$ de umidade de 0,80 $\mathrm{g} / \mathrm{cm}^{3}$ e é considerada madeira pesada e dura ao corte (Gonzaga, 2006).

- Amendoim (Pterogyne nitens) - madeira de massa específica aparente a $15 \%$ de umidade de $0,77 \mathrm{~g} / \mathrm{cm}^{3}$, é considerada pesada (Mainieri e Chimelo, 1989). É de fácil trabalhabilidade e recebe um bom acabamento (Lorenzi, 1992).

Contudo, algumas incertezas sobre as matériasprimas e as variáveis do processo de produção e qualidade do piso engenheirado constituem limitações que podem comprometer a produção industrial. Em função dessas incertezas e da grande exigência do mercado em relação à qualidade de acabamento do produto, justifica-se a importância deste estudo, o qual se baseia na necessidade de gerar alternativas para a melhoria da qualidade dos produtos e da eficiência dos processos de transformação industrial da madeira.

Nesse contexto, o presente trabalho teve como objetivo estudar a relação entre a velocidade de avanço da serra de fita horizontal múltipla e a qualidade final das lamelas de quatro espécies tropicais utilizadas na produção do piso engenheirado de madeira.

b) Coleta de material

Para o desenvolvimento da pesquisa, foram selecionadas quatro espécies tropicais utilizadas na produção do piso engenheirado: jatobá (Hymenaea courbaril), muiracatiara (Astronium lecointei), amendoim (Pterogyne nitens) e sucupira (Bowdichia nítida). Foram coletadas 60 amostras para cada espécie, sendo 30 com largura de $82,5 \mathrm{~mm}$ e 30 com largura de $127 \mathrm{~mm}$, para obtenção das lamelas. As espécies jatobá e muiracatira apresentaram $27 \mathrm{~mm}$ de espessura nominal, originando cinco lamelas. Já a sucupira e o amendoim, com dimensões $22 \mathrm{~mm}$ de espessura nominal, originaram quatro lamelas.

c) Processo de obtenção das lamelas

O processo de obtenção das lamelas é composto por três etapas consecutivas, envolvendo os seguintes equipamentos: Plaina - S4S (Surfaced Four Sides), serra fita horizontal múltipla e lixadeira calibradora. A plaina tem por objetivo a calibração da espessura e da largura nas quatro faces da peça de madeira. A serra fita horizontal múltipla é composta por quatro serras fita, com a qual é realizado o desdobro da peça de madeira após seu processamento de aplainamento. Neste processo, a peça de madeira é transformada em lamelas. Em seguida, as lamelas passam pela lixadeira calibradora para calibração da espessura das lamelas. O estudo analisou a variação da espessura após a passagem pela serra fita horizontal múltipla.

d) Plano experimental

Para a organização das informações a serem coletadas, utilizou-se um plano experimental, estruturado por um modelo de tabela de tratamentos, referenciado pela codificação T1, T2, T3 e T4, e classificado por espécies para a obtenção das características do processo de produção de lamelas, como mostra a Tabela 1.

e) Obtenção da espessura das lamelas

As lamelas tiveram suas espessuras medidas com o auxílio de um paquímetro digital em seis pontos 
equidistantes, para detectar a variação da espessura de corte (Figura 1).

\section{f) Avaliação do experimento}

Para o controle de classificação da espessura das lamelas, adotou-se o procedimento estabelecido pela empresa. De acordo com o manual de qualidade, as espessuras nominais de $22 \mathrm{~mm}$ originam quatro lamelas e as de $27 \mathrm{~mm}$ originam cinco lamelas, sendo aceitas lamelas com variação de espessura entre 4,25 e $4,70 \mathrm{~mm}$, utilizadas neste estudo. Os valores

Tabela 1. Plano experimental para a produção de lamelas.

Table 1. Experimental plan for the production of lamellae.

\begin{tabular}{|c|c|c|c|c|c|c|c|}
\hline & \multicolumn{7}{|c|}{ Jatobá } \\
\hline \multirow{5}{*}{$\mathrm{T} 1$} & Velocidade & \multicolumn{2}{|c|}{$8 \mathrm{~m} / \mathrm{min}$} & \multicolumn{2}{|c|}{$12 \mathrm{~m} / \mathrm{min}$} & \multicolumn{2}{|c|}{$16 \mathrm{~m} / \mathrm{min}$} \\
\hline & Largura & $82,5 \mathrm{~mm}$ & $127 \mathrm{~mm}$ & $82,5 \mathrm{~mm}$ & $127 \mathrm{~mm}$ & $82,5 \mathrm{~mm}$ & $127 \mathrm{~mm}$ \\
\hline & Espessura & $27 \mathrm{~mm}$ & $27 \mathrm{~mm}$ & $27 \mathrm{~mm}$ & $27 \mathrm{~mm}$ & $27 \mathrm{~mm}$ & $27 \mathrm{~mm}$ \\
\hline & No de peças & 10 & 10 & 10 & 10 & 10 & 10 \\
\hline & $\mathrm{N}^{\circ}$ de lamelas & 50 & 50 & 50 & 50 & 50 & 50 \\
\hline \multirow{6}{*}{$\mathrm{T} 2$} & \multicolumn{7}{|c|}{ Muiracatiara } \\
\hline & Velocidade & \multicolumn{2}{|c|}{$8 \mathrm{~m} / \mathrm{min}$} & \multicolumn{2}{|c|}{$12 \mathrm{~m} / \mathrm{min}$} & \multicolumn{2}{|c|}{$16 \mathrm{~m} / \mathrm{min}$} \\
\hline & Largura & $82,5 \mathrm{~mm}$ & $127 \mathrm{~mm}$ & $82,5 \mathrm{~mm}$ & $127 \mathrm{~mm}$ & $82,5 \mathrm{~mm}$ & $127 \mathrm{~mm}$ \\
\hline & Espessura & $27 \mathrm{~mm}$ & $27 \mathrm{~mm}$ & $27 \mathrm{~mm}$ & $27 \mathrm{~mm}$ & $27 \mathrm{~mm}$ & $27 \mathrm{~mm}$ \\
\hline & $\mathrm{N}^{\circ}$ amostra & 10 & 10 & 10 & 10 & 10 & 10 \\
\hline & $\mathrm{N}^{\circ}$ de lamelas & 50 & 50 & 50 & 50 & 50 & 50 \\
\hline \multirow{6}{*}{ T3 } & \multicolumn{7}{|c|}{ Sucupira } \\
\hline & Velocidade & \multicolumn{2}{|c|}{$8 \mathrm{~m} / \mathrm{min}$} & \multicolumn{2}{|c|}{$12 \mathrm{~m} / \mathrm{min}$} & \multicolumn{2}{|c|}{$16 \mathrm{~m} / \mathrm{min}$} \\
\hline & Largura & $82,5 \mathrm{~mm}$ & $127 \mathrm{~mm}$ & $82,5 \mathrm{~mm}$ & $127 \mathrm{~mm}$ & $82,5 \mathrm{~mm}$ & $127 \mathrm{~mm}$ \\
\hline & Espessura & $22 \mathrm{~mm}$ & $22 \mathrm{~mm}$ & $22 \mathrm{~mm}$ & $22 \mathrm{~mm}$ & $22 \mathrm{~mm}$ & $22 \mathrm{~mm}$ \\
\hline & $\mathrm{N}^{\circ}$ amostra & 10 & 10 & 10 & 10 & 10 & 10 \\
\hline & No de Lamelas & 40 & 40 & 40 & 40 & 40 & 40 \\
\hline & \multicolumn{7}{|c|}{ Amendoim } \\
\hline & Velocidade & \multicolumn{2}{|c|}{$8 \mathrm{~m} / \mathrm{min}$} & \multicolumn{2}{|c|}{$12 \mathrm{~m} / \mathrm{min}$} & \multicolumn{2}{|c|}{$16 \mathrm{~m} / \mathrm{min}$} \\
\hline \multirow[t]{4}{*}{$\mathrm{T} 4$} & Largura & $82,5 \mathrm{~mm}$ & $127 \mathrm{~mm}$ & $82,5 \mathrm{~mm}$ & $127 \mathrm{~mm}$ & $82,5 \mathrm{~mm}$ & $127 \mathrm{~mm}$ \\
\hline & Espessura & $22 \mathrm{~mm}$ & $22 \mathrm{~mm}$ & $22 \mathrm{~mm}$ & $22 \mathrm{~mm}$ & $22 \mathrm{~mm}$ & $22 \mathrm{~mm}$ \\
\hline & $\mathrm{N}^{\circ}$ amostra & 10 & 10 & 10 & 10 & 10 & 10 \\
\hline & No de lamelas & 40 & 40 & 40 & 40 & 40 & 40 \\
\hline
\end{tabular}

Fonte: Os autores, segundo a metodologia de pesquisa.

Source: The authors, according to the research methodology.

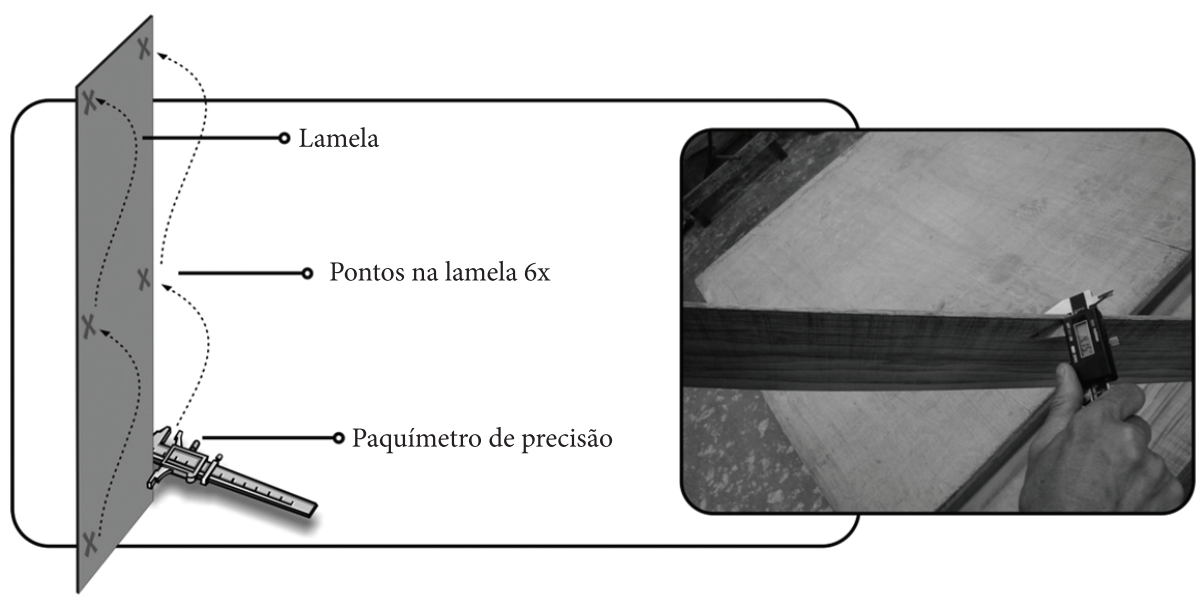

Figura 1. Obtenção das medidas de espessura das lamelas. Fonte: autores.

Figure 1. Obtaining measurements of the thickness of the lamellae. 
de controle considerados pelo departamento de qualidade da empresa analisada estão apresentados na Tabela 2.

$\mathrm{Na}$ medida em que as lamelas de $82,5 \mathrm{~mm}$ e $127,0 \mathrm{~mm}$ de largura foram obtidas a partir de espessuras de $22 \mathrm{~mm}$ (4 lamelas) e $27 \mathrm{~mm}$ (5 lamelas), a espessura padrão utilizada nas comparações estatísticas foi de 4,25 a 4,70 mm. A partir desta faixa de valor, os dados foram resumidos em três categorias: a primeira englobou as espessuras que se encontravam dentro dos limites especificados e foi nomeada "Dentro do Padrão", igual a Grupo 1. O segundo grupo envolveu as espessuras menores que 4,25 mm e foi denominado de "Abaixo do Padrão", igual a grupo 2. Finalmente, o último conjunto relacionou as medidas que eram maiores do que 4,70 mm e foi nomeado "Acima do Padrão", igual a Grupo 3.

Para verificar se as medições obtidas eram dependentes ou não, foram desenvolvidas as seguintes hipóteses: H0: não existe relação entre as velocidades de avanço da serra fita múltipla e as porcentagens de lamelas dentro dos padrões de controle de qualidade; e H1: existe dependência entre estas variáveis. Em seguida, foi obtido o cruzamento dos dados envolvidos, realizada a análise da tabela de contingência, bem como o qui-quadrado.

Em paralelo ao processo de medição, foram identificados, por meio visual, os defeitos existentes na superfície das lamelas ocasionados ou não pelo processo de corte da serra fita múltipla. Foram observados três tipos de ocorrências - marca de serra, marca de plaina e ausência de marcas -, originando três categorias: "Marca de Serra", igual a Grupo 1; "Marca de Plaina", igual a Grupo 2, e
“Ausência de Marcas", igual a Grupo 3. As hipóteses elaboradas para esta situação foram: H0: não existe relação entre as velocidades de avanço e as marcas de serra nas lamelas; e H1: existe dependência entre estas variáveis.

Uma vez que não é possível fazer suposições quanto ao modelo de distribuição de probabilidade da população em função dos dados categorizados, o método de tabulação cruzada com o uso da análise qui-quadrado $\left(\chi^{2}\right)$ de Pearson foi aplicado para descrever as relações entre os conjuntos das variáveis categóricas envolvidas. Segundo Hair (2005), esta estatística possui o propósito de mostrar se, de fato, há significância estatística da associação ou da dependência entre as distribuições de frequência de dois ou mais grupos. Para Pallant (2007), o quiquadrado de Pearson testa a hipótese de que a linha e a coluna são variáveis independentes. Quanto menor o valor do significado, é menos provável que as variáveis sejam independentes. Como suporte para a realização dos cálculos estatísticos, foi utilizado o programa SPSS 14.0 for Windows, um programa especializado em análises estatísticas de matrizes de dados, pelo qual é possível obter relatórios tabulados, gráficos e plotagens de distribuições utilizados nas análises descritivas e de associação entre as variáveis.

\section{RESULTADOS E DISCUSSÃO}

Na Tabela 3, pode ser observada a distribuição das frequências entre a velocidade de avanço e os padrões de espessura.

Em função de serem produzidos diferentes números de lamelas por espécie, a discussão foi conduzida com as porcentagens obtidas. De maneira

Tabela 2. Controle de espessura das lamelas.

Table 2. Control of thickness of lamellae.

\begin{tabular}{|c|c|c|c|c|c|}
\hline \multicolumn{6}{|c|}{ Equipamento } \\
\hline \multicolumn{2}{|c|}{ S4S } & \multicolumn{2}{|c|}{ Serra fita horizontal } & \multicolumn{2}{|c|}{ Lixadeira calibradora } \\
\hline $\begin{array}{c}\text { Largura } \\
\text { (mm) }\end{array}$ & $\begin{array}{c}\text { Espessura } \\
(\mathbf{m m})\end{array}$ & $\begin{array}{c}\text { Largura } \\
(\mathbf{m m})\end{array}$ & $\begin{array}{c}\text { Espessura } \\
(\mathbf{m m})\end{array}$ & Largura (mm) & Espessura (mm) \\
\hline 86,6 & 22,0 a 22,8 & 82,5 & 4,25 a 4,70 & 82,5 & 3,70 a 3,90 \\
\hline 131,0 & 22,0 a 22,8 & 127,00 & 4,25 a 4,70 & 127,0 & 3,70 a 3,90 \\
\hline 86,6 & 26,5 a 27,0 & 82,5 & 5,60 a 6,00 & 82,5 & 4,90 a 5,10 \\
\hline 131,0 & 26,5 a 27,0 & 127,00 & 5,60 a 6,00 & 127,0 & 4,90 a 5,10 \\
\hline
\end{tabular}

Fonte: Luz (2008), com base nos manuais de qualidade da empresa.

Source: Luz (2008) based on the company's quality manual. 
Tabela 3. Variação da espessura obtida no processo de produção de lamelas nas Velocidades de avanço de 8,12 e 16 $\mathrm{m} / \mathrm{min}$ para as espécies jatobá, muiracatiara, sucupira e amendoim.

Table 3. Contingency table between Standard thickness and speed of advancement of 8, 12 and $16 \mathrm{~m} / \mathrm{min}$ for the species jatobá, muiracatiara sucupira and amendoim.

\begin{tabular}{|c|c|c|c|c|c|c|c|c|c|}
\hline \multirow{5}{*}{ Jatobá } & \multirow{3}{*}{$\begin{array}{c}\text { Espessura } \\
\text { Dentro do padrão }\end{array}$} & \multicolumn{6}{|c|}{ Velocidade de avanço } & \multirow{2}{*}{\multicolumn{2}{|c|}{ Total }} \\
\hline & & \multicolumn{2}{|c|}{$8 \mathrm{~m} / \mathrm{min}$} & \multicolumn{2}{|c|}{$12 \mathrm{~m} / \mathrm{min}$} & \multicolumn{2}{|c|}{$16 \mathrm{~m} / \mathrm{min}$} & & \\
\hline & & 209 & $69,7 \%$ & 164 & $54,7 \%$ & 181 & $60,3 \%$ & 554 & $61,6 \%$ \\
\hline & Abaixo do padrão & 19 & $6,3 \%$ & 45 & $15,0 \%$ & 22 & $7,3 \%$ & 86 & $9,6 \%$ \\
\hline & Acima do padrão & 72 & $24,0 \%$ & 91 & $30,3 \%$ & 97 & $32,3 \%$ & 260 & $28,9 \%$ \\
\hline Total & & 300 & $100,0 \%$ & 300 & $100,0 \%$ & 300 & $100,0 \%$ & 900 & $100,0 \%$ \\
\hline \multirow{3}{*}{ Muiracatiara } & Dentro do padrão & 200 & $66,7 \%$ & 182 & $60,7 \%$ & 185 & $61,7 \%$ & 567 & $63,0 \%$ \\
\hline & Abaixo do padrão & 36 & $12,0 \%$ & 31 & $10,3 \%$ & 34 & $11,3 \%$ & 101 & $11,2 \%$ \\
\hline & Acima do padrão & 64 & $21,3 \%$ & 87 & $29,0 \%$ & 81 & $27,0 \%$ & 232 & $25,8 \%$ \\
\hline Total & & 300 & $100,0 \%$ & 300 & $100,0 \%$ & 300 & $100,0 \%$ & 900 & $100,0 \%$ \\
\hline \multirow{3}{*}{ Sucupira } & Dentro do padrão & 153 & $63,8 \%$ & 158 & $65,8 \%$ & 164 & $68,3 \%$ & 475 & $66,0 \%$ \\
\hline & Abaixo do padrão & 18 & $7,5 \%$ & 23 & $9,6 \%$ & 27 & $11,3 \%$ & 68 & $9,4 \%$ \\
\hline & Acima do padrão & 69 & $28,8 \%$ & 59 & $24,6 \%$ & 49 & $20,4 \%$ & 177 & $24,6 \%$ \\
\hline Total & & 240 & $100,0 \%$ & 240 & $100,0 \%$ & 240 & $100,0 \%$ & 720 & $100,0 \%$ \\
\hline \multirow{3}{*}{ Amendoim } & Dentro do padrão & 130 & $54,2 \%$ & 112 & $46,7 \%$ & 124 & $51,7 \%$ & 366 & $50,8 \%$ \\
\hline & Abaixo do padrão & 37 & $15,4 \%$ & 37 & $15,4 \%$ & 35 & $14,6 \%$ & 109 & $15,1 \%$ \\
\hline & Acima do padrão & 73 & $30,4 \%$ & 91 & $37,9 \%$ & 81 & $33,8 \%$ & 245 & $34,0 \%$ \\
\hline Total & & 240 & $100,0 \%$ & 240 & $100,0 \%$ & 240 & $100,0 \%$ & 720 & $100,0 \%$ \\
\hline
\end{tabular}

geral, independentemente da largura das peças e da velocidade de avanço, do total de lamelas produzidas, a sucupira foi a espécie que apresentou a maior frequência de lamelas dentro do padrão, com $66,0 \%$, seguida pela muiracatiara $(63,0 \%)$ e pelo jatobá $(61,6 \%)$. O menor aproveitamento obtido foi o amendoim, com 50,8\%.

Quando analisadas individualmente, as maiores frequências encontradas "Dentro do Padrão" estão relacionadas à velocidade $8 \mathrm{~m} / \mathrm{min}$ do jatobá, com 209 (69,7\%), seguidas pela muiracatiara, com 200 (66\%); diversamete, o amendoim foi à espécie que apresentou a menor frequência, com somente 112 $(46,7 \%)$ lamelas "Dentro do Padrão" na velocidade de $12 \mathrm{~m} / \mathrm{min}$.

Os motivos que levaram à baixa produção de lamelas dentro do padrão nas três velocidades estudadas da espécie amendoim estão provavelmente relacionados com as características da espécie - Massa Especifica Aparente média $\left(0,77 \mathrm{~g} / \mathrm{cm}^{3}\right)$, textura média a grossa e grã irregular -, podendo ainda o equipamento ter influenciado diretamente nos resultados. As serras fitas podem ter sofrido flambagem, causando o desbitolamento das lamelas em virtude das características da madeira. Este fato fica evidenciado quando se observa a alta porcentagem de lamelas acima do padrão para o amendoim (34\%), o que vai de encontro com os resultados obtidos. As lamelas produzidas dentro e acima do padrão podem ser utilizadas no processo de produção de piso engenheirado, sendo que somente as lamelas que apresentaram espessura abaixo do padrão foram desclassificadas no processo de produção. As variações encontradas neste estudo, relacionadas com as propriedades da madeira na produção de lamelas, vão ao encontro com Silva (2002) e Kininmonth e Whitehouse (1991).

Na Figura 2, pode ser observada a distribuição de lamelas produzidas abaixo do padrão nas três velocidades estudadas para cada espécie. As espécies apresentaram um comportamento semelhante de desclassificação nas três velocidades, com exceção do jatobá, com $12 \mathrm{~m} / \mathrm{min}$, que apresentou um elevado índice $(15,0 \%)$ de lamelas abaixo do padrão, bem acima dos valores observados para as velocidades de 8 e $16 \mathrm{~m} / \mathrm{min}$. Estes resultados provavelmente foram causados por problemas operacionais que não foram observados no momento do teste. Para Coletti et al. (2010) e Silva (2002), a falta de capacitação técnica é uma das fortes razões da perda de qualidade, resultando em desclassificação do material. Este alto índice de lamelas desclassificadas chama a atenção 


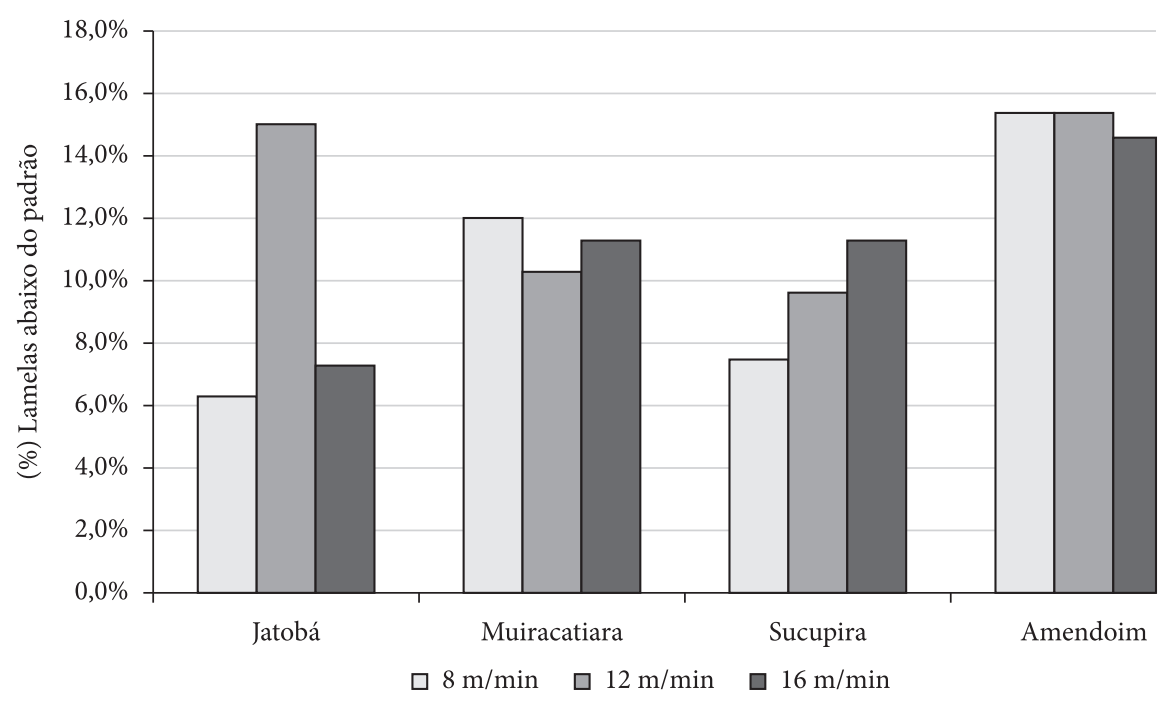

Figura 2. Percentual de lamelas produzidas "Abaixo do Padrão" nas velocidades de $8 \mathrm{~m} / \mathrm{min}, 12 \mathrm{~m} / \mathrm{min}$ e $16 \mathrm{~m} / \mathrm{min}$ para as espécies jatobá, muiracatiara, sucupira e amendoim.

Figure 2. Percentage of lamellae produced below the standard at speeds of $8 \mathrm{~m} / \mathrm{min}, 12 \mathrm{~m} / \mathrm{min}$ and $16 \mathrm{~m} / \mathrm{min}$ for the species jatobá, muiracatiara sucupira and amendoim.

em razão do alto valor da madeira, podendo ocorrer durante o processo normal de produção de lamelas e passando despercebido pela produção.

A muiracatiara e o amendoim foram as espécies que apresentaram, nas três velocidades estudadas, índices médios de, respectivamente, $11,2 \%$ e $15,1 \%$ de lamelas abaixo do padrão, com pouca influência da velocidade de avanço. Em seu estudo, Coletti et al. (2010) observaram índice de 2,3\% de lamelas com variação de espessura, estando bem abaixo dos resultados encontrados neste estudo. Os menores índices de lamelas rejeitadas foram obtidos na espécie jatobá, nas velocidades de $8 \mathrm{~m} / \mathrm{min}$ e $16 \mathrm{~m} / \mathrm{min}$, totalizando $19(6,3 \%)$ e $22(7,3 \%)$ peças descartadas no processo, para cada velocidade, respectivamente. Considerando-se o alto valor da matéria-prima utilizada, estes índices elevados devem ser observados e reduzidos. O alto índice de lamelas abaixo do padrão pode estar relacionado com as características da madeira e com o ajuste do equipamento (Lucas Filho, 2004).

A sucupira foi a espécie que apresentou a tendência esperada nos resultados, ou seja, com o aumento da velocidade de avanço, ocorreu aumento na porcentagem de lamelas abaixo do padrão. Com velocidade de avanço de $8 \mathrm{~m} / \mathrm{min}$, obtevese uma porcentagem de 7,5\% de lamelas rejeitadas e, com $16 \mathrm{~m} / \mathrm{min}$, tal porcentagem atingiu $11,3 \%$.
Estes índices estão bem acima dos obtidos para o jatobá, nas respectivas velocidades. Esta tendência foi esperada porque, com o aumento da velocidade de avanço, a serra apresenta maior facilidade em flambar, causando variação na espessura das lamelas. Os resultados obtidos estão de acordo com as recomendações sugeridas por Lucas Filho (2004) e Silva (2002), segundo as quais o equipamento e a madeira são as principais variáveis que causam perdas de qualidade.

Todas as lamelas que apresentaram espessura abaixo do padrão seguiram o processo normal de produção, passando para a fase seguinte, pela lixadeira calibradora, para finalização da espessura, e posterior classificação de qualidade. Foram consideradas lamelas fora do padrão de qualidade (desclassificadas), as lamelas que apresentaram espessura abaixo da aceitável (3,7 a 3,9 mm) e marcas de serra ou de plaina nas duas faces. Quando as lamelas apresentaram espessura dentro do limite aceitável e defeito em uma das faces, foram consideradas de boa qualidade.

A Figura 3 apresenta a distribuição das espessuras, considerando se as mesmas estavam dentro, acima ou abaixo do padrão estabelecido pelo controle de qualidade da empresa analisada. Pode-se observar que as três categorias ocuparam posições percentuais bem definidas, variando da seguinte forma: "Dentro do Padrão", de 46,7\% a 69,7\%; "Acima do Padrão", 
de $20,4 \%$ a $37,9 \%$, e "Abaixo do Padrão", de 6,3\% a $15,40 \%$.

O qui-quadrado (Tabela 4) demonstra que para a muiracatiara, $\operatorname{com} \chi^{2}(4)=5,041,(p>0,05)$, a sucupira, com $\chi^{2}(4)=5,567,(p>0,05)$, e o amendoim, com $\chi^{2}$ $(4)=3,442$, $(p>0,05)$, a hipótese nula foi rejeitada, indicando que não existe relação entre as velocidades de avanço e as porcentagens de lamelas dentro dos padrões de controle de qualidade. Contudo, para o jatobá, com $\chi^{2}(4)=23,639$, $(\mathrm{p}<0,05)$, a hipótese nula não foi refutada, ou seja, as variáveis velocidade de avanço e o padrão de espessura das lamelas são dependentes.

A Tabela 5 apresenta os principais defeitos observados no processo de produção de lamelas, variando a velocidade de avanço nas quatro espécies estudadas após a passagem pela serra de fita horizontal múltipla.

Das lamelas de jatobá inspecionadas, 217 (48,2\%) apresentaram alguma marca na superfície, das quais $184(40,9 \%)$ eram originadas por serra e $33(7,3 \%)$ por plaina. Das marcas de serra, 78 eram marcas do tipo "leve", 66 eram do tipo "média", 40 eram do tipo "profunda". A tabela de contingência evidenciou que a maior concentração de marcas provocadas por serra estava relacionada com as velocidades 8 e $12 \mathrm{~m} / \mathrm{min}$, cada uma apresentando $65(43,3 \%)$ observações.

Das lamelas analisadas de muiracatiara, 166 $(36,9 \%)$ apresentaram algum tipo de ocorrência,

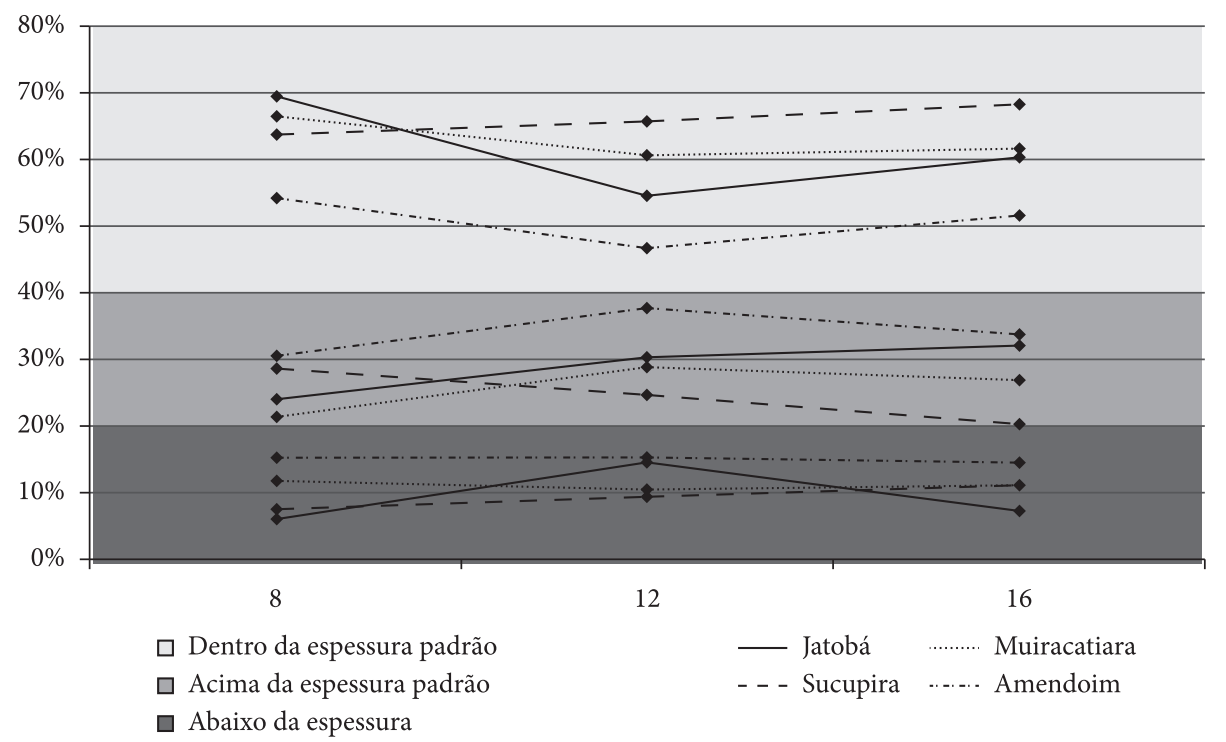

Figura 3. Percentual do padrão de espessuras em relação à velocidade de avanço.

Figure 3. Percentage of standard thickness versus speed for the advancement.

Tabela 4. Resultados do teste Qui-Quadrado $\left(\chi^{2}\right)$ para a variação da espessura das lamelas.

Table 4. Results of chi-square $\left(\chi^{2}\right)$ for the variatio of the thickness of lamellae.

\begin{tabular}{lccc}
\multicolumn{1}{c}{ Pearson Chi-Square } & Value & df & Valor-p \\
\hline Jatobá & $23,639^{\mathrm{a}}$ & 4 &, 000 \\
Muiracatiara & $5,041^{\mathrm{b}}$ & 4 &, 283 \\
Sucupira & $5,567^{\mathrm{c}}$ & 4 &, 234 \\
Amendoim & $3,442^{\mathrm{d}}$ & 4 &, 487
\end{tabular}

a) Células ( $0,0 \%$ ), que se espera contam menos do que 5 . A contagem mínima esperada é de 28,67 . b) 0 (células, $0 \%$ ), que se espera contam menos do que 5. A contagem mínima esperada é de 33,67. c) 0 (células, $0 \%$ ), que se espera contam menos do que 5. A contagem mínima esperada é de 22,67. d) 0 (células, $0 \%$ ), que se espera contam menos do que 5 . A contagem mínima esperada é de 36,33 .

a) 0 cells $(, 0 \%)$ have expected count less than 5 . The minimum expected count is 28,67 . b) 0 cells $(, 0 \%)$ have expected count less than 5. The minimum expected count is 33,67 . c) 0 cells $(, 0 \%)$ have expected count less than 5 . The minimum expected count is 22,67 . d) 0 cells $(, 0 \%)$ have expected count less than 5 . The minimum expected count is 36,33 . 
sendo 150 marcas de serra e 16 marcas de plaina. Para este tipo de madeira (esta espécie), a velocidade $8 \mathrm{~m} / \mathrm{min}$ foi a que apresentou a maior frequência tanto para marca de serra quanto para marca de plaina, com 63 (42\%) e 11 (7,3\%), respectivamente.

Ao contrário do jatobá e da muiracatiara, que apresentaram o maior número de ocorrências na velocidade $8 \mathrm{~m} / \mathrm{min}$, a sucupira e o amendoim apresentaram as maiores frequências de marca de serra e de plaina na velocidade $16 \mathrm{~m} / \mathrm{min}$, ou seja, $56(55 \%)$ e 62 (51,6\%), respectivamente. A Figura 4 ilustra as frequências das ocorrências observadas durante a inspeção visual, bem como o percentual de lamelas que não apresentaram nenhum tipo de marca.

Pode-se observar na Figura 4 que o jatobá e a muiracatiara apresentaram os maiores índices de ausência de ocorrências, pois não foi encontrado nenhum tipo de marca em 86 (57,3\%) das lamelas inspecionadas da primeira madeira e em 122 $(81,3 \%)$ lamelas da segunda. Estes percentuais estão relacionados à velocidade $16 \mathrm{~m} / \mathrm{min}$. Por outro

Tabela 5. Defeitos obtidos no processo de produção de lamelas nas velocidades de avanço de 8,12 e $16 \mathrm{~m} / \mathrm{min}$, para as espécies jatobá, muiracatiara, sucupira e amendoim.

Table 5. Defects obtained in the process of production of lamellae in the speed for the Advancement of 8,12 and $16 \mathrm{~m} / \mathrm{min}$. for the species jatobá, muiracatiara, sucupira and amendoim.

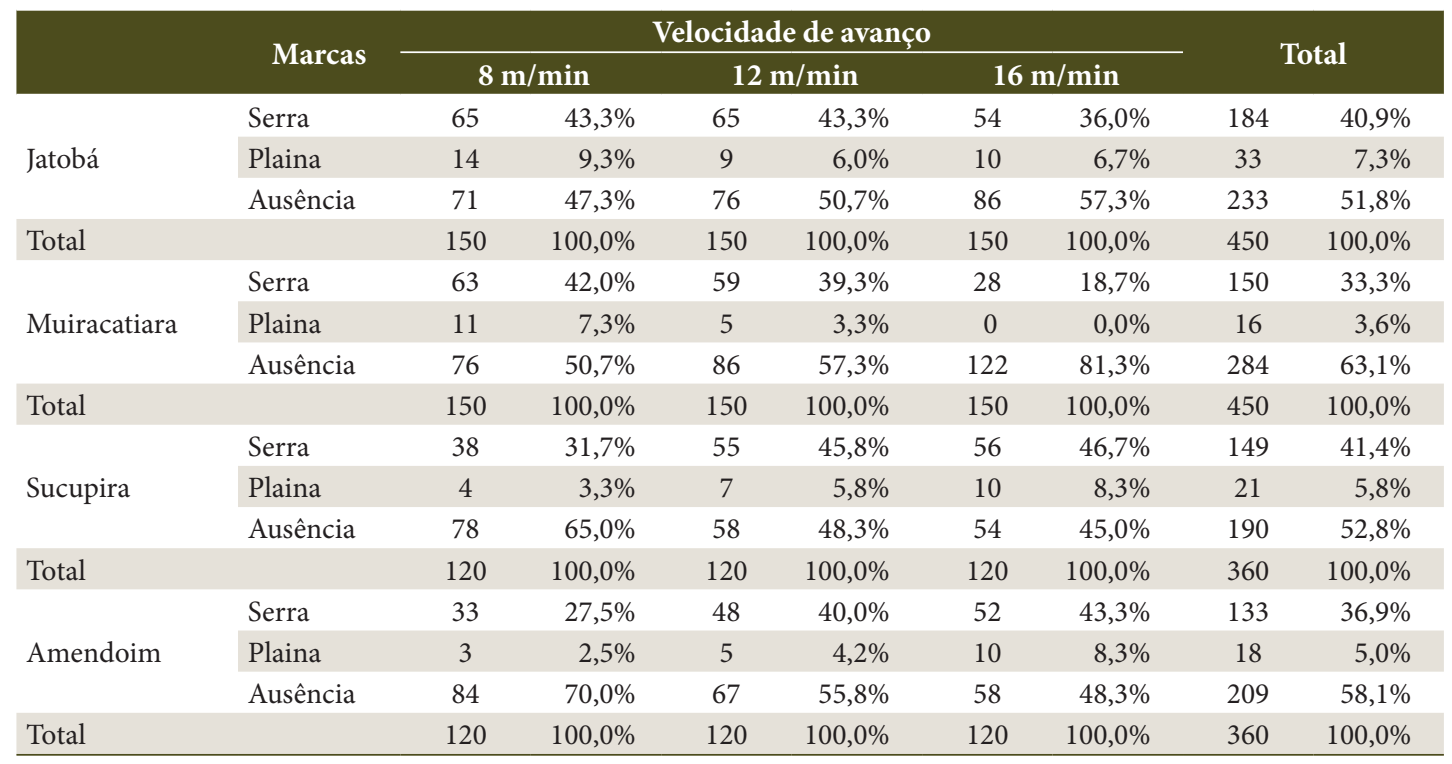

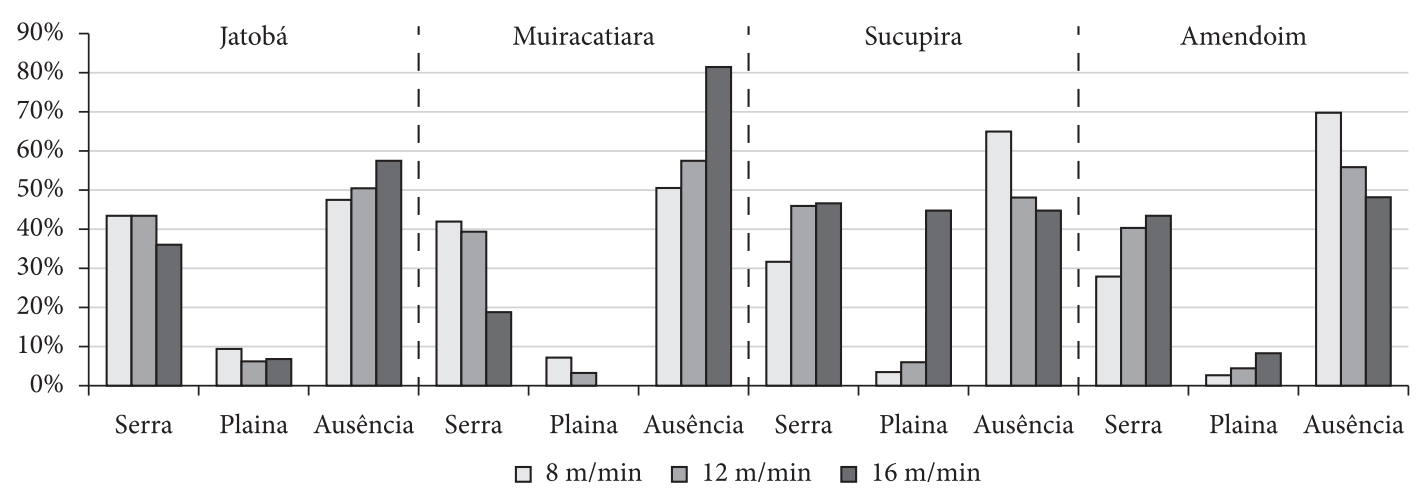

Figura 4. Percentual das ocorrências observadas em relação à velocidade de avanço.

Figure 4. Percentage of occurrences observed in relation to the advancement. 
lado, a sucupira e o amendoim apresentaram as maiores ausências de marcas na velocidade $8 \mathrm{~m} /$ min, sendo 78 (65\%) e $84(70 \%)$, respectivamente. $\mathrm{Na}$ Tabela 6, pode-se observar que a muiracatiara, com $\chi^{2}(4)=38,421,(\mathrm{p}<0,05)$, a sucupira, com $\chi^{2}(4)=11,913,(\mathrm{p}<0,05)$ e o amendoim, com $\chi^{2}$ $(4)=13,864,(\mathrm{p}<0,05)$, apresentaram resultados estatisticamente significativos, indicando que a hipótese nula foi rejeitada, ou seja, existe relação entre as velocidades de avanço e as marcas de serra e plaina nas lamelas. Contudo, para o jatobá, com $\chi^{2}$ $(14)=4,090,(p>0,05)$, aceitou-se a hipótese nula de que não existe relação entre as velocidades de avanço e as marcas de serra e plaina nas lamelas.

$\mathrm{Na}$ Figura 5, podem ser observadas as lamelas desclassificadas no processo de produção utilizando serra de fita horizontal múltipla. O jatobá foi a espécie que mais contribuiu para a desclassificação das lamelas (10,67\%), enquanto que o amendoim apresentou o menor percentual de lamelas desclassificadas $(6,44 \%)$. Em média, foram obtidas $7,73 \%$ de lamelas desclassificadas. A velocidade de $12 \mathrm{~m} / \mathrm{min}$ causou, em média, maior índice de lamelas desclassificadas $(9,67 \%)$ e a de $8 \mathrm{~m} / \mathrm{min}$, a menor desclassificação $(5,17 \%)$. Na velocidade de $8 \mathrm{~m} / \mathrm{min}$, pode ser observada a influência da espécie no que tange às propriedades físicas e anatômicas, sendo que o amendoim apresentou a menor desclassificação (2,67\%).

Os resultados demonstram que, independentemente da velocidade de avanço utilizada, obtiveram-se elevados índices de lamelas desclassificadas, resultando em elevadas perdas no processo de produção das mesmas. Observou-se que, com a menor velocidade, ocorreram as menores perdas durante o processo de produção de lamelas. Os parâmetros de processo (espécie de madeira

Tabela 6. Resultados do teste Qui-Quadrado $\left(\chi^{2}\right)$.

Table 6. Results of chi-square $\left(\chi^{2}\right)$.

\begin{tabular}{lcccc}
\multicolumn{1}{c}{ Pearson Qui-quadrado } & Valor & df & Valor-p & N. Casos Válidos \\
\hline Jatobá & $4,090^{\mathrm{a}}$ & 4 &, 394 & 450 \\
Muiracatiara & $38,421^{\mathrm{b}}$ & 4 &, 000 & 450 \\
\hline Sucupira & $11,913^{\mathrm{c}}$ & 4 &, 018 & 360 \\
Amendoim & $13,864^{\mathrm{d}}$ & 4 &, 008 & 360 \\
\hline
\end{tabular}

a) 0 célula (, $0 \%)$ tem esperado contar menos de 5 . A contagem mínima esperada é de 11,00 ; b) 0 célula (, $0 \%)$ tem esperado contar menos de 5 . A contagem mínima esperada é de 5,33 ; c) 0 célula $(, 0 \%)$ tem esperado contar menos de 5 . A contagem mínima esperada é de 7,$00 ;$ d) 0 célula (, $0 \%$ ) tem esperado contar menos de 5 . A contagem mínima esperada é de 6,00.

a) 0 cell $(, 0 \%)$ have expected count less than 5 . The minimum count is 11.00 expected, b) 0 cell $(, 0 \%)$ have expected count less than 5. The minimum count is expected to 5.33 , c) 0 cell $(, 0 \%)$ have expected count less than 5 . The minimum count is expected to be 7.00 d) 0 cell $(, 0 \%)$ have expected count less than 5 . The minimum expected count is 6.00 .

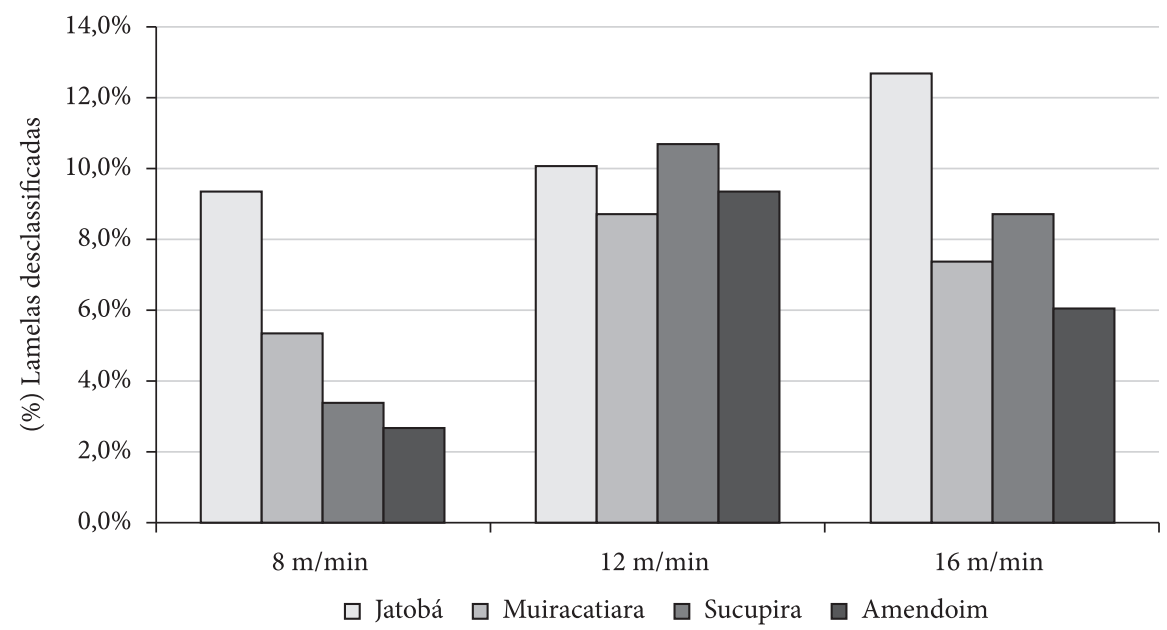

Figura 5. Percentual de lamelas desclassificadas no processo de produção.

Figure 5. Percentage of lamellae disqualified in the production process. 
utilizada, equipamento e capacitação técnica), citados por Lucas Filho (2004), Silva (2002), Latorraca (2000) e Coletti et al. (2010), foram os principais fatores que influenciaram nos resultados obtidos.

\section{CONCLUSÕES}

Em função dos resultados obtidos, concluiu-se que:

- O amendoim (Pterogyne nitens Tul) apresentou maior aproveitamento na produção de lamelas, enquanto que o jatobá (Hymenaea courbaril L.) foi a espécie que sofreu maior perda no processo de produção;

- A velocidade de avanço que apresentou os menores índices de desclassificação de lamelas foi de $8 \mathrm{~m} / \mathrm{min}$, sendo a mais indicada para produção de lamelas;

- A velocidade de avanço de $12 \mathrm{~m} / \mathrm{min}$ apresentou, em média, as maiores perdas $(9,67 \%)$ na produção de lamelas para todas as espécies estudadas.

\section{AGRADECIMENTOS}

À Empresa Scandian Wood Floors.

\section{STATUS DA SUBMISSÃO}

Recebido: 14/12/2011

Aceito: 27/11/2012

Publicado: 28/02/2013

\section{AUTOR(ES) PARA CORRESPONDÊNCIA}

\section{Raquel Marchesan}

Universidade Federal do Paraná - UFPR, Av.

Prefeito Lothário Meissner, 900, CEP 80210-170,

Curitiba, PR, Brasil

e-mail: raqmarchesan@gmail.com

\section{Ricardo Jorge Klitzke}

Departamento de Tecnologia e Utilização de Produtos Florestais, Universidade Federal do Paraná - UFPR, Av. Prefeito Lothário Meissner, 900, CEP 80210-170, Curitiba, PR, Brasil e-mail: rjkklitzke@gmail.com

\section{REFERÊNCIAS}

Associação Nacional dos Produtores de Pisos de Madeira - ANPM. Madeiras para piso. [cited 2010 May 7]. Available from: <www.anpm.org.br/atividades/ bibliotecas/madeiras.html $>$.

Coletti J, Bonduelle GM, Iwakiri S. Avaliação de defeitos no processo de fabricação de lamelas para pisos de madeira engenheirados com uso de ferramentas de controle de qualidade. Acta Amazônica 2010; 40: 135-140. http://dx.doi.org/10.1590/S004459672010000100017

Gonzaga AL. Madeira: Uso e conservação. Brasília: IPHAN, Monumenta; 2006. 246 p. Cadernos técnicos, n. 6 .

Hair JF, Black B, Babin B, Anderson RE, Tatham RL. Multivariate Data Analysis. 5. ed. Porto Alegre: Bookman, 2005.

Instituto Brasileiro do Meio Ambiente e dos Recursos Naturais Renováveis - IBAMA. Madeiras brasileiras. [cited 2011 Aug 18]. Available from: http://www.ibama.gov.br/lpf/madeira/caracteristicas. php? $\mathrm{ID}=28 \&$ caracteristica $=52$.

Instituto Brasileiro de Desenvolvimento Florestal - IBDF. Madeiras da Amazônia, Características e Utilização: estação Experimental de Curuá-Uma. Brasília: Dpq-LPF; 1988. v. 2.

Kininmonth JA, Whitehouse LJ. Properties and use of New Zealand radiata pine: wood properties. New Zealand: Forest Research Institute, 1991. v.1.

Latorraca JVF, Albuquerque CEC. Efeito do rápido crescimento sobre as propriedades da madeira. Floresta e Ambiente 2000, 7(1): 279-291.

Lorenzi H. Árvores brasileiras: manual de identificação e cultivo de plantas arbóreas nativas do Brasil. Nova Odessa: Plantarum, 1992.

Lucas Filho FC. Análise da usinagem da madeira visando a melhoria de processos em indústrias de móveis [tese]. Florianópolis: Universidade Federal de Santa Catarina; 2004

Luz JRM. Controle de qualidade do processo produtivo de piso engenheirado da empresa Novopiso S.A [monografia]. Curitiba: Universidade Federal do Paraná; 2008. 64p.

Mainieri C, Chimelo JP. Fichas de características das madeiras brasileiras. São Paulo: Instituto de pesquisas tecnológicas - IPT; 1989.

Pallant J. SPSS: Survival Manual. New York: McGraw Hill; 2007.

Silva JRM. Relações da usinabilidade e aderência do verniz com as propriedades fundamentais do Eucalyptus grandis Hill ex. Maiden [tese]. Curitiba: Universidade Federal do Paraná; 2002. 179 p

Stemmer GE. Ferramentas de corte I. 5. ed. Florianópolis: Ed. da UFSC; 2001. 